\title{
Um acontecimento na vida do pintor-viajante, de César Aira: o procedimento intempestivo.
}

\section{Michel Mingote Ferreira de Azara (UFMG)}

Resumo: A novela Um acontecimento na vida do pintor-viajante do escritor argentino César Aira acompanha os passos do pintor Joahan Moritz Rugendas em sua viagem realizada à Argentina, na primeira metade do século XIX. Tal viagem fora interrompida por um acontecimento que iria marcar a forma do pintor-viajante de representar a "paisagem natural" do país. O artigo considerará o conceito de imagem-dialética, de Walter Benjamin, e as considerações intempestivas de Friedrich Nietzsche, para realizar a leitura da obra.

Palavras-chave: Johann Moritz Rugendas, César Aira, imagem dialética.

O Único fio que o unia à realidade era a urgência em seguir de perto os acontecimentos

Um acontecimento na vida do pintor-viajante

O pintor-viajante Johann Moritz Rugendas percorreu no século XIX Brasil, Peru, Bolívia, Argentina e Uruguai, contribuindo com suas pinturas para a representação visual da América Latrina. Filho, neto e bisneto de prestigiados pintores de gênero, Rugendas foi um dos maiores criadores da iconografia americana, visto como "um pintor versátil, cujo leque temático vai desde os estudos naturalistas da paisagem até as mais sofisticadas composições de temas históricos". "Sua primeira viagem à América Latina foi ao Brasil, como ilustrador da expedição do naturalista Georg Henrich Von Langsdorff, de 1822 até 1824, que rendeu a publicação em fascículos do Viagem Pitoresca Através do Brasil, álbum de litografias e comentários sobre o país. Na obra do pintor, de acordo com César Aira, literatura e viagem se entrelaçavam como numa corda.

A novela de César Aira começa apresentando uma breve bibliografia de Rugendas, inclusive suas relações com o cientista-naturalista e explorador prussiano Alexander Von Humboldt( 1769-1859):

Rugendas foi um pintor de gênero. Seu gênero foi a fisionomia da natureza, procedimento criado por Humboldt. Este grande naturalista foi o pai de uma disciplina que, em boa mediada morreu com ele: a Erdtheorie (teoria da terra), ou physique Du Monde (descrição física do mundo), uma espécie de geografia artística, uma captação estética do mundo, a ciência da paisagem". 2

Humboldt reinventou a América enquanto natureza, uma natureza vista como extraordinária, dramática, que "apequena os homens, determina o seu ser, excita

Cadernos Benjaminianos, n. 3, Belo Horizonte, jan.-jun. 2011, p.87-97 
suas paixões, desafia seus poderes de percepção"3. Segundo Mary Louise Pratt essa natureza selvagem e gigantesca, que "apequena os homens", seria vista por meio de uma consciência planetária, que entrelaçava a linguagem visual e emotiva com a classificatória e técnica. Um tipo inteiramente novo de discurso sobre a natureza era proposto, e na apresentação dos seus "quadros" da natureza, a especificidade da ciência era combinada com a estética do sublime. Nesse sentido, Rugendas representa sinteticamente em suas pinturas a "fisionomia da natureza".

Após a breve introdução bibliográfica, a novela de César Aira acompanha os passos de Rugendas quando este parte do Chile e chega à Argentina, no final de dezembro de 1837, acompanhado pelo pintor alemão Robert Krause. A viagem realizada à Argentina é apontada como uma necessidade sentida por Rugendas: “ Somente ali ele pensava poder encontrar o reverso de sua arte...essa perigosa ilusão o perseguiu durante toda a vida..."4. É Interessante notar que na bibliografia de Rugendas, a partir de sua Segunda viagem à Argentina, em 1845, se percebe uma mudança de estilo em sua pintura "tão evidente como inusitada", como salientara DIENNER \& COSTA. Retomando os trabalhos dedicados aos Araucanos ${ }^{5}$, iniciados no final de 1835, Rugendas elabora composições barrocas, totalmente distantes de sua pintura precedente, como as tela de 1845 e 1848 EL Rapto, (figura 1) onde é flagrada uma tentativa de apreender, reter o instante, desistindo de uma representação minuciosa da realidade. Dessa forma, Rugendas se afasta de uma concepção classicista do quadro, aproximando, de maneira experimental, dos princípios da pintura romântica francesa, se apresentando como um precursor da pintura impressionista. Nas duas telas de Rugendas, El rapto, tidas como uma "invenção de sua fantasia"6 se evocam as cenas de batalhas do pintor barroco Georg Philipp I Rugendas, bisavô de Rugendas, iniciador da dinastia de pintores e especialista na representação de batalhas. Como afirma DIENNER \& COSTA, na longa lista de óleos pintados por Georg Philipp até 1700, aparecem um a um todos os elementos de composição que Johan Mortiz Rugendas utiliza:

O recurso de composições circulares nas cenas do primeiro plano, a sucessão dos outros episódios de luta representados em diferentes planos do quadro, o enfático jogo de contrastes de luz e sombra, mudanças bruscas na escala e dimensão das figuras, assim como o caráter de esboço nos planos de fundo, para marcar a profundidade de campo. ${ }^{7}$

Ainda segundo os autores, os modelos barrocos levaram Johan Mortiz Rugendas a uma nova concepção pictórica, na qual já não se oculta o processo da pintura, e, mais ainda, a pincelada parece compor a dinâmica do quadro, à medida que acentua a direção do movimento. Na novela de César Aira, a prática nova iniciada por Rugendas, o esboço a óleo é apresentada como uma inovação que a história da arte registrou como tal, e, talvez, um acontecimento na vida do pintor-viajante tenha possibilitado essa ruptura, presente em pinturas como El Rapto. A primeira viagem à Argentina é apresentada como crucial na vida do pintor-viajante. Uma carta de Humboldt a Rugendas, apresentada na novela, supostamente inibe sua viagem à Argentina: "não desperdice seu talento, que consiste sobretudo em desenhar o que é realmente excepcional na paisagem(...)" ${ }^{\prime}$. Na novela de César Aira, literatura e biografia, fabulação e relato também se entrelaçavam como numa corda.

Cadernos Benjaminianos, n. 3, Belo Horizonte, jan.-jun. 2011, p.87-97 


\section{Figura 1}

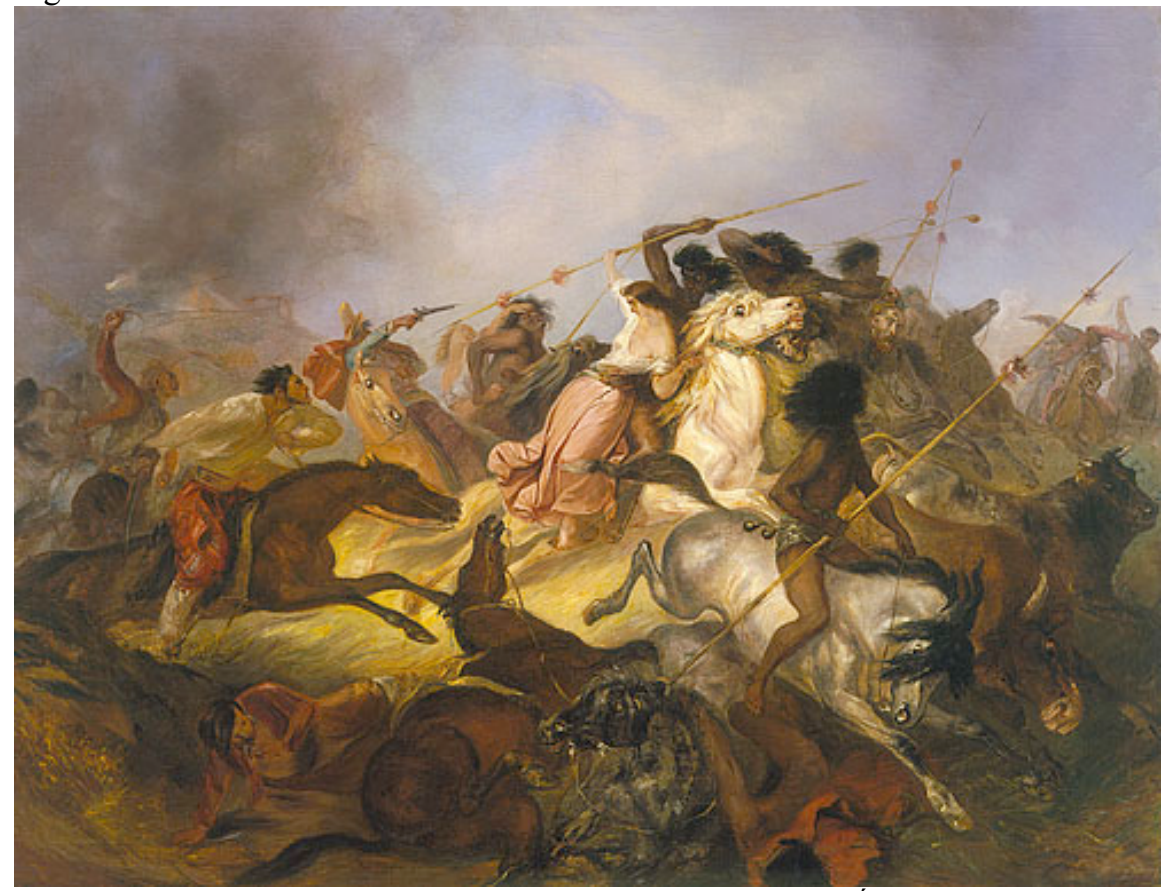

(Juan Mauricio Rugendas- El Rapto- rescate de una cautiva. 1848, Óleo sobre tela, colección privada.)

Fonte:http://www.buenosaires.gov.ar/areas/cultura/arteargentino/00sigloxix/01gr_05_rug endas_1.php

\section{Um acontecimento na vida do pintor-viajante}

Em busca de algo que o obrigaria a criar um novo procedimento o pintor-viajante de César Aira parte da cidade de Mendoza rumo a Buenos Aires. Uma das ânsias do pintor era presenciar ataques indígenas, que eram descritos como verdadeiros tufões humanos, que por natureza não obedeciam a nenhum oráculo ou calendário. Era impossível prevê-los:

Poderia ocorrer um deles daqui a uma hora, ou não haver nenhum até o ano que vem (aproveitando que estamos em janeiro). Rugendas teria pago para poder pintar um desses ataques. Todos os dias do mês, acordava com a secreta esperança de que aquele era o dia. (...) Ao que parece, eram muito imediatos, coisas de horas ou minutos. Os cães babavam, as galinhas bicavam seus próprios ovos, as formigas se multiplicavam, as plantas floresciam, etc. ${ }^{9}$

Entretanto, Rugendas acabaria encontrando outra coisa. Perdidos numa planície inóspita, Rugendas abandona o guia e seu acompanhante Krause, e parte em busca

Cadernos Benjaminianos, n. 3, Belo Horizonte, jan.-jun. 2011, p.87-97 
de água. Logo em seguida o tempo fecha e Rugendas e seu cavalo são atingidos por dois raios:

O segundo raio o fulminou menos de quinze segundos depois do primeiro. Foi muito mais forte e teve efeitos muito mais devastadores. Eles voaram uns vinte metros, acesos e crepitando como uma fogueira fria. Seguramente por efeito de composição atômica que os corpos e os elementos estavam sofrendo naquela ocasião, a queda não foi fatal. Ela foi como acolchoada e aconteceu aos rebotes. (...) A circunstância era anormal ao extremo. O cavalo se movia pelo chão feito um caranguejo e milhares de células de fogo estalavam ao seu redor, formando uma espécie de auréola generalizada que se deslocava com ele que já não parecia afetá-lo. Gritavam, o homem e o cavalo? Provavelmente estava num espasmo de mudez. $^{10}$

Depois dos dois raios, Rugendas é arrastado pelo cavalo por alguns metros, sendo encontrado somente no outro dia totalmente desfigurado.A partir daí, o pintor volta com Krause para Mendonça onde é tratado à base de morfina misturada com ópio e aos poucos recomeça sua atividade de pintor.

\section{Um procedimento intempestivo}

"Nos domínios que nos ocupam, não há conhecimento a não ser fulgurante. O texto é o trovão que faz ouvir o seu bramido longo tempo depois".

Walter Benjamin.

O texto de Nietzsche, "consideração intempestiva sobre a utilidade e os inconvenientes da História para a vida", contrapõe ao peso excessivo do passado o umbral do instante, que se ergue para o homem com o esquecimento que lhe é próprio e a felicidade que suscita. A intenção do filósofo, ao pesar as vantagens e desvantagens da história para a vida, é questionar o historicismo, as visões cientificistas da história, principalmente a filosofia da história Hegeliana, que acredita que a história sempre foi escrita pelos vencedores, sendo assim causal, linear e homogênea. Dessa forma, o texto de Nietzsche investiga o valor e o não valor da história para a vida, numa perpectiva contrária ao perspectivismo citado anteriormente, buscando determinar o limite a partir do qual o passado deve ser esquecido, de modo que não se torne o "coveiro do presente". Além disso é necessário atingir um estado de não-historicidade, de cegueira, de esquecimento para captar a força do presente:

Mas, tanto na menor como na maior felicidade, há sempre algo que faz com que a felicidade seja uma felicidade: a faculdade de sentir as coisas, durante todo o tempo em que dura a felicidade, fora de qualquer perspectiva histórica. Aquele que não sabe instalar-se no limiar do instante, esquecendo todo o passado, aquele que não sabe, como uma deusa da vitória, colocar-se de pé uma vez sequer, sem medo e sem vertigem, este

Cadernos Benjaminianos, n. 3, Belo Horizonte, jan.-jun. 2011, p.87-97 
não saberá jamais o que é felicidade, e o que é ainda pior: ele jamais estará em condições de tornar os outros felizes. ${ }^{11}$

Esse estado a-histórico, considerado pelo filósofo o mais injusto da terra, limitado, ingrato com o passado, é também extremamente necessário para que um artista desenvolva a sua obra, para que todo grande acontecimento histórico seja produzido:

Imagine-se um homem perturbado e arrastado por uma violenta paixão, seja por uma mulher ou por uma grande ideia: todo o seu universo ficaria então transformado. Quando olha para trás, ele se sente cego; quando aguça os ouvidos à sua volta, ouve ruídos estranhos, como um rumor surdo desprovido de significado; mas o que ele chega a perceber agora jamais o tinha percebido assim: tão próximo, tão palpável, tão colorido, tão sonoro, tão luminoso, que parece impregnar todos os seus sentidos ao mesmo tempo. Todos os seus julgamentos de valor são modificados e invalidados: ele não está mais em condições de avaliar uma tal riqueza, pois pode somente percebê-la. ${ }^{12}$

Esta espécie de "supremacia do instante" é necessária para a invenção, para o acontecimento. Conforme a concepção de Nietzsche, "as potências a-históricas são o esquecimento e a ilusão". Nesse sentido a história se subordina à vida, se subordina à arte. Ainda de acordo com o filósofo, o elemento histórico e o a-histórico são igualmente necessários, o que se deve combater é o excesso de história. Os três tipos de história considerados por Nietzsche - a tradicionalista, a monumental e a crítica são úteis à vida, mas o conhecimento do passado só é útil na medida em que serve ao futuro e ao presente, na medida em que serve à vida.

Voltemos à narrativa de Aira. O pintor-viajante se encontra em estado lastimável. Afora os espasmos e as dores que por vezes o acometiam, seu rosto estava totalmente desfigurado: " A boca tinha se contraído num botão de rosa cheio de pregas e rebordos. O queixo estava deslocado para a direita e fazia uma grande cova, que nem uma colher de sopa" ${ }^{13}$ Seu rosto mudava de cor, tremia e "visto a partir de uma tal goma elástica mágica, o mundo devia parecer diferente, pensava Krause. Não eram apenas as lembranças próximas que se tingiam de alucinações, mas também o mundo cotidiano." ${ }^{14}$ Além disso, Rugendas tinha:

sua pobre mente alterada e seu organismo em ruínas sofria com a luz direta. Suas pupilas não tinham capacidade de contrai-se mais, tornaram-se como pontos. A droga anulava o sistema elástico e a iluminação ficava inassimilável. Era como se ele houvesse dado mais um passo para dentro dos quadros. ${ }^{15}$

Fora neste estado de cegueira que o pintor-viajante presenciara o tão esperado ataque dos indígenas. Vestindo uma mantilha, dopado de morfina/ópio e tendo espasmos freqüentes, Rugendas consegue desenhar a cena fluida, onde o que interessava era "a fugacidade, a organização dentro do acaso, a velocidade da organização" ${ }^{16}$ E essa fugacidade se reproduzia no procedimento dos pintores: havia

Cadernos Benjaminianos, n. 3, Belo Horizonte, jan.-jun. 2011, p.87-97 
um equilíbrio de proximidades e distâncias do qual precisavam tirar o máximo proveito. As fugas e perseguições simultâneas davam a cena uma plasticidade infinita.

$\mathrm{O}$ acontecimento na vida do pintor viajante aparece como crucial para que ocorra a quebra da ordem da representação, para a abertura a uma pintura que não mais entraria numa estrita relação mimética, mas potencializando os procedimentos da pintura, onde "cada traço correspondente da realidade visível, numa equivalência de um para um. Ao contrário, a função do traço era construtiva."17 A pintura recebe uma carga de opacidade, de auto-referencialidade que mina a possibilidade da representação. O tom cômico e picaresco em que é apresentado Rugendas, aparece para mostrar a falha na representação: "No caso de Rugendas, com os nervos do rosto todos seccionados, 'a ordem da representação' que se originava chegava ao destino, ou melhor dizendo, chegava (e isso é que era pior), mas deformado por dezenas de mal-entendidos sinápticos". 18

É nessa cegueira intempestiva que Rugendas rompe com o estatuto da representação e busca reter o instante, se distanciando da concepção clacissista do quadro e aproximando da concepção da pintura romântica francesa. ${ }^{19}$ As pinturas do romântico inglês William Turner (figura 2) também mantêm correspondências com a obra de Rugendas, uma vez que ele é visto como um precurssor do impressionismo, se se considerar a técnica do estudo a óleo utilizada por ele: "estudos rápidos sem pretensão de elaborar composições, que se propõe a captar o primeiro impacto das cores da paisagem em toda a sua intensidade e frescura, chegará a ser dominante na obra posterior de Rugendas." 20 Nesse sentido, o personagem de César aira se aproxima daquele homem Nietzschiano, "perturbado e arrastado por uma violenta paixão", num estado a-histórico, cego, que mergulha no instante para subordinar a história à vida, a história à arte:

(...) é somente com o olhar artístico que é possível fazer uma descrição das coisas do passado: não há "fatos", não há "verdades" históricas, só há composições, formatações, montagens, ilusões, que podem inclusive ser úteis à vida, quer dizer, podem funcionar como alavancas e exemplos modelares. $^{21}$

Essa relação entre história e vida também pode ser vista na novela de César aira. Rugendas e Krause concordavam que a vantagem que a história tinha era a de se saber como se faziam as coisas. Entretanto, Rugendas ia um passo mais adiante e formula, a título de hipótese, que o silêncio dos relatos não implicava nenhuma perda, uma vez que a geração atual, ou uma futura, podia voltar a vivenciar esses mesmos acontecimentos do passado, sem necessidade de que fossem relatados, por mera ação combinatória ou pelo "império dos acontecimentos". De acordo com essa proposição, o que devia transmitir-se era:

O conjunto de "ferramentas" com o qual se podia reinventar, com a inocência espontânea da ação, o que havia sucedido no passado. $\mathrm{O}$ mais valioso que os homens fizeram, o que valia a pena que voltasse a acontecer. E a chave desta ferramenta era o estilo. Segundo esta teoria, então, a arte era mais útil que o discurso. ${ }^{22}$

Cadernos Benjaminianos, n. 3, Belo Horizonte, jan.-jun. 2011, p.87-97 
Nesse trecho da novela se percebe ecos das considerações intempestivas de Nietzsche e também do mito do eterno retorno, formulado pelo filósofo. O que está em jogo na reflexão de Rugendas, talvez seja a possibilidade de invenção que cabe a arte, de inovação (Rugendas e o esboço a óleo?) que se sobrepõe à causalidade da história, e possibilita a repetição, repetição da diferença, puro acontecimento, ou nos termos de Derrida, o jogo da repetição ou a repetição do jogo. Como afirma Flora Sussekind, no livro Tal Brasil, Qual Romance, a preocupação com a repetição em Nietzsche, e pensadores de cunho pós-estruturalista como Deleuze, Derrida e Foucault, não implica uma recusa da história. O que se recusa "é fazer da história uma continuidade progressista. Repetição não exclui transformação, revolução". ${ }^{23}$ Nesse sentido repetição se associa à ruptura e a diferença, e a diferença na repetição é que constitui o novo, que destrói a identidade simulada e abre espaço para a diferença. Ou conforme Derrida, o jogo da repetição abre a possibilidade da afirmação Nietzschiana, "afirmação alegre do jogo do mundo e da inocência do devir, a afirmação de um mundo de signos sem erro, sem verdade, sem origem, oferecido a uma interpretação ativa". ${ }^{24}$

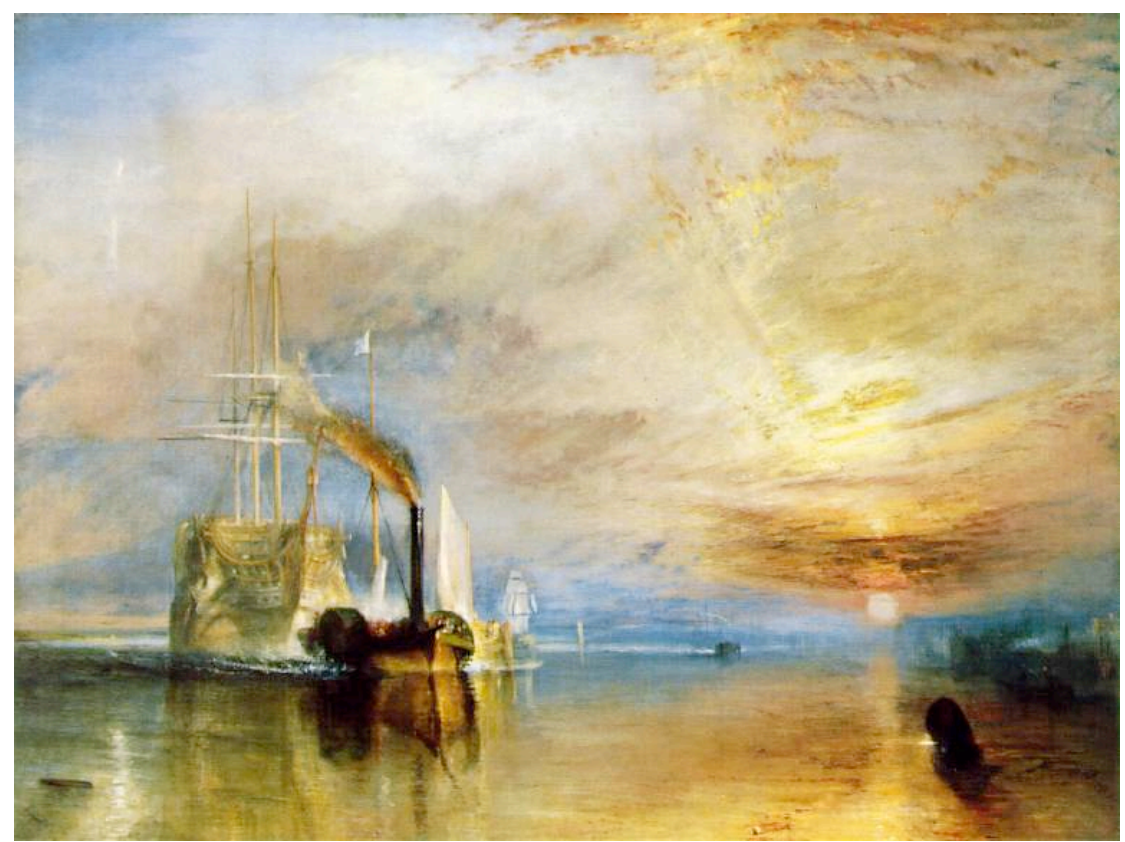

(Joseph Mallord William Turner: "The Fighting 'Temeraire' tugged to her last berth to be broken up" 1838; Oil on canvas, 91 x $122 \mathrm{~cm}$; National Gallery, London).

Fonte: http://www.ibiblio.org/wm/paint/auth/turner/i/temeraire.jpg

Além dos autores citados por Flora Sussekind, outro pensador importante considerando essa relação é Walter Benjamin, que, em seus escritos, rompe a causalidade da história e questiona o historicismo, a ideia de progresso, de finalidade da história, ou seja, apresenta a concepção de história aberta. Um dos conceitos formulados pelo autor para problematizar essa relação é o de imagem dialética. De acordo com o filósofo: 
Não é que o passado lança luz sobre o presente ou que o presente lança sua luz sobre o passado; mas a imagem é aquilo em que o ocorrido encontra o agora num lampejo, formando uma constelação. Em outras palavras: a imagem é a dialética na imobilidade (...) a relação do ocorrido com o agora é dialética - não uma progressão, e sim uma imagem, que salta. - Somente as imagens dialéticas são imagens autênticas (isto é: não-arcaicas), e o lugar onde as encontramos é a linguagem. ${ }^{25}$

A leitura que Didi-Huberman faz dessas imagens, presente no livro $O$ que vemos, $o$ que nos olha, compreende que as obras, enquanto inventam formas novas, modificam as regras de sua própria tradição, de sua própria ordem discursiva. Nesse sentido, o autor considera a obra poética de Baudelaire, por exemplo, enquanto imagem dialética, imagem de memória e crítica ao mesmo tempo, imagem "de uma novidade radical que reinventa o originário - transforma e inquieta duravelmente os campos discursivos circundantes; enquanto tal, essa forma (...) traz consigo efeitos teóricos agudos, efeitos de conhecimento. ${ }^{26}$ Sob o mesmo ponto de vista, é possível fazer uma aproximação entre essa concepção de imagem e a obra pictórica de Moritz Rugendas. A técnica do estudo a óleo, permitiu a Rugendas questionar o estatuto da representação clássica, uma vez que "cada traço do desenho não deveria reproduzir um traço correspondente da realidade visível, numa equivalência de um para um". O artista busca captar o acontecimento, já não oculta o processo da pintura, "mais ainda, a pincelada parece compor a dinâmica do quadro, à medida que acentua a direção do movimento". ${ }^{27}$ A retomada do barroco, o rompimento de uma concepção clacissista do quadro, é, na narrativa de César Aira, resultado de um acontecimento na vida do pintor-viajante, um relâmpago, uma tempestade. A partir desse ponto, o procedimento de Rugendas se torna intempestivo, dialético. Se, conforme Walter Benjamin, a imagem dialética é aquela imagem do passado que entra numa conjunção fulgurante e instantânea com o presente - a retomada do barroco na pintura de Rugendas e a conseguente inovação do procedimento? - a ruptura causada pela tela El rapto de Rugendas se aproxima, nesse ponto, da formulação de imagem dialética de acordo com a leitura de Didi-Huberman: uma imagem crítica, que produz ela mesma uma leitura crítica do seu próprio presente, na conflagração que ela produz com o seu próprio pretérito. A tese V, presente em Sobre o conceito de história, de Walter Benjamin, também apresenta essa concepção de imagem como algo fugaz: “A verdadeira imagem do passado passa célere e furtiva. É somente como imagem que lampeja justamente no instante de sua recognoscibilidade, para nunca mais ser vista, que o passado tem de ser capturado." ${ }^{28}$ Os ataques indígenas cuja imagem fora captada por Rugendas também obedeciam a essa intempestividade: "Na região, eram considerados como verdadeiros tufões humanos, mas por natureza não obedeciam a nenhum oráculo ou calendário. Era impossível prevê-los." ${ }^{29}$

Tanto a consideração intempestiva de Nietzsche quanto a concepção de imagem dialética em Walter Benjamin configuram a possibilidade de uma outra escrita da história, uma outra práxis historiográfica, que rompe o encadeamento linear, causal, contínuo. No entanto, na acepção Nietzschiana a intempestividade se dá através de certo grau de esquecimento, através da supremacia do instante, da transfiguração da história e de certa cegueira a-histórica daquele que é arrebatado do contínuo 
histórico. Estado que lembra a cegueira em que Rugendas, após ser atingido pelo relâmpago, trabalhava:

Na cegueira, seus movimentos executavam trejeitos fantasiosos e o modo como manipulava os papéis chamou a atenção.Ocorreu-lhe fazer uma classificação das cenas e, como não as conseguia ver direito, envolvia-se tanto com elas que reproduzia as posturas dos índios com toda a extensão do seu corpo e com as imagináveis restrições impostas por seus nervos dilacerados. ${ }^{30}$

Quanto às formulações Benjaminianas, a dialética em obra, a invenção de um novo procedimento está na "telescopagem" de uma imagem do passado com a do presente, na ruptura com o gênero "fisionomia da natureza" formulado por Humboldt, na transvaloração da pintura de Rugendas, que buscou nas imagens passadas, no barroco, uma pintura do acontecimento, um procedimento intempestivo. Nesse sentido, César Aira potencializa sua literatura ao fabular sobre a trajetória de Rugendas, que aparece no livro não como uma equivalência "de um para um" com a biografia do pintor-viajante e suas pinturas, mas num entrelaçamento (como numa corda) de literatura e vida, na qual a própria literatura apresenta-se como acontecimento, como um curto-circuito na ordem da representação, de reinvenção de uma história já contada, no caso, a do pintorviajante Rugendas.

Ao longo do dia, produziu-se uma evolução que não se completou em direção a um saber não-mediado. Tem-se que levar em conta que o ponto de partida era uma mediação muito trabalhosa. O procedimento Humboldtiano era um sistema de mediações: a representação fisionômica se interpunha entre o artista e a natureza. A percepção direta ficava descartada por definição. E, não obstante, era inevitável que a mediação deixasse de existir, não tanto por sua eliminação, mas por um excesso que a tornava mundo, nu eprimitivo, em seus signos. No fim das contas, é algo que acontece todos os dias. Alguém começa a conversar com o próximo e quer saber o que ele está pensando. Parece impossível conseguir averiguar isso se não for através de uma extensa série de inferências. O que é que existe de mais encerrado e mediado que a atividade psíquica? E mesmo assim, esta se expressa na linguagem, que está no ar, e que somente pede para ser ouvida. A pessoa se atira contra as palavras e, sem saber, já chegou ao outro lado e está no corpo-a-corpo com o pensamento do outro. Mutatis mutandis, acontece o mesmo com um pintor em relação ao mundo visível. É o que acontecia ao pintor-viajante. O que o mundo dizia, era o mundo. $^{31}$

\begin{abstract}
A novel "Um acontecimento na vida do pintor-viajante" of the Argentine writer CésarAira follows in the footsteps of
\end{abstract}

Cadernos Benjaminianos, n. 3, Belo Horizonte, jan.-jun. 2011, p.87-97 
the painter Joahan Moritz Rugendas held on his trip toArgentina in the first half of the nineteenth century. This trip was interrupted by anevent that would mark the shape of the painter-traveler represent the "natural landscape " of the country. The article will consider the concept of imagedialectic, by Walter Benjamin, and the untimely considerations of Friedrich Nietzsche, to take a reading of the work.

Keywords: César Aira, image-dialetic, Johann Moritz Rugendas.

\section{Referências Bibliográficas}

AIRA, César. Um acontecimento na vida do pintor viajante. Trad. Paulo Andrade Lemos. Rio de Janeiro: Nova Fronteira, 2006.

BENJAMIN, Walter. Passagens Trad. TIEDEMANN, Rolf; BOLLE, Willi; MATOS, Olgaria C. F.; ARON, Irene. Belo Horizonte: Editora UFMG; São Paulo: Imprensa Oficial do Estado de São Paulo, 2006.

DERRIDA, Jacques. A escritura e a diferença. São Paulo. Perspectiva. 1971.

DIENER, Pablo; COSTA, Maria de Fátima G. (Maria de Fatima Gomes). A América de Rugendas: obras e documentos. São Paulo: Estação Liberdade: Kosmos, 1999.

DIENER, Pablo; COSTA, Maria de Fátima. Rugendas e o Brasil. São Paulo: Capivara, 2002.

LOWY, Michael. Walter Benjamin : aviso de incêndio : uma leitura das teses "Sobre o conceito de história". Trad. BRANT, Wanda Nogueira Caldeira; GAGNEBIN, JeanneMarie; MULLER, Marcos Lutz. São Paulo: Boitempo, 2005.

NIETZSCHE, Friedrich Wilhelm. Segunda consideração intempestiva: da utilidade e desvantagem da história para a vida. Rio de Janeiro: Relume Dumará, 2003.

PRATT, Mary Louise. Alexander Von Humbolt e a invenção da América. In: Revista Estudos Históricos, Rio de Janeiro, vol. 4. n. 8, 1991, p. 151-165

SOBRINHO. Noéli Correia de Melo Sobrinho. Apresentação e comentário. In: NIETZSCHE, Friedrich Wilhelm. Segunda consideração intempestiva: da utilidade e desvantagem da história para a vida. Rio de Janeiro: Relume Dumará, 2003.

SÜSSEKIND, Flora. Tal Brasil, qual romance?: uma ideologia estética e sua história : o naturalismo. Rio de Janeiro: Achiame, 1984.

Cadernos Benjaminianos, n. 3, Belo Horizonte, jan.-jun. 2011, p.87-97 


\section{Notas}

${ }^{1}$ DIENER E COSTA. A América de Rugendas, p.13-14.

${ }^{2}$ AIRA. Um acontecimento na vida do pintor viajante, p.11.

${ }^{3}$ PRATT. Alexander Von Humbolt e a invenção da América, p.2120.

${ }^{4}$ AIRA. Um acontecimento na vida do pintor viajante, p.10.

${ }^{5}$ Os mapuches (na língua mapudungun, gente da terra) são um povo indígena da região centro-sul do Chile e do sudoeste da Argentina. São conhecidos também como araucanos, denominação que caiu em desuso na contemporaneidade e que é desprezada por esta etnia e que no entanto, predomina na historiografia por um longo período que abarca os primeiros contatos com os espanhóis até meados do século XIX.

${ }^{6}$ DIENER \& COSTA. A América de Rugendas, p.199.

${ }^{7}$ DIENER E COSTA, 1999.p.25.

${ }^{8}$ AIRA. Um acontecimento na vida do pintor viajante, p.13.

${ }^{9}$ AIRA. Um acontecimento na vida do pintor viajante, p.32.

${ }^{10}$ AIRA. Um acontecimento na vida do pintor viajante, 50-51.

${ }^{11}$ NIETZSCHE. II Consideração Intempestiva sobre a utilidade e os inconvenientes da História para a vida, p.72.

${ }^{12}$ NIETZSCHE. II Consideração Intempestiva sobre a utilidade e os inconvenientes da História para a vida, p.76.

${ }^{13}$ AIRA. Um acontecimento na vida do pintor viajante, p.60.

${ }_{15}^{14}$ AIRA. Um acontecimento na vida do pintor viajante, p.61.

${ }^{15}$ AIRA. Um acontecimento na vida do pintor viajante, p.88.

${ }^{16}$ AIRA. Um acontecimento na vida do pintor viajante, p.94.

${ }^{17}$ AIRA. Um acontecimento na vida do pintor viajante, p.71.

${ }^{18}$ AIRA. Um acontecimento na vida do pintor viajante, p.126.

${ }^{19}$ DIENER \& COSTA. A América de Rugendas, p.26.

${ }^{20}$ DIENER \& COSTA. Rugendas e o Brasil, p.27.

${ }^{21}$ SOBRINHO. Escritos sobre história, p.45-46.

${ }^{22}$ AIRA. Um acontecimento na vida do pintor viajante, p.41.

${ }^{23}$ SUSSEKIND. Tal Brasil, Qual Romance, p.64.

${ }^{24}$ DERRIDA. A escritura e a diferença, p.248.

${ }^{25}$ BENJAMIN. Passagens, p.504.

${ }^{26}$ DIDI-HUBERMAN. O que vemos o que nos olha, p.178.

${ }^{27}$ DIENER \& COSTA. A América de Rugendas, p. 25.

${ }^{28}$ BENJAMIN. Sobre o conceito de História apud LOWY, Aviso de incêndio, p.62.

${ }^{29}$ AIRA.Um acontecimento na vida do pintor viajante, p.31.

${ }^{30}$ AIRA. Um acontecimento na vida do pintor viajante, p.116-117.

${ }^{31}$ AIRA. Um acontecimento na vida do pintor viajante, p.113-114. 